\title{
Does prior spine surgery or instrumentation affect surgical outcomes following 3-column osteotomy for correction of thoracolumbar deformities?
}

\author{
Darryl Lau, MD, ${ }^{1}$ Andrew K. Chan, MD, ${ }^{1}$ Vedat Deverin, MD, ${ }^{2}$ and Christopher P. Ames, MD' \\ Departments of ${ }^{1}$ Neurological Surgery and ${ }^{2}$ Orthopedic Surgery, University of California, San Francisco, California
}

\begin{abstract}
OBJECTIVE Adult spinal deformity (ASD) develops in the setting of asymmetrical arthritic degeneration, and can also be due to iatrogenic causes, such as prior surgery. Many patients who present with ASD have undergone prior spine surgery with instrumentation. Unfortunately, contemporary studies that evaluate the effect of prior surgery or instrumentation on perioperative outcomes, readmission rates, and need for reoperation are lacking.

METHODS All ASD patients who underwent a 3-column osteotomy performed by the senior author at the authors' institution for correction of thoracolumbar spinal deformity between 2006 and 2016 were identified. The authors compared surgical outcomes between primary (first-time) and revision cases. Further subgroup analysis was conducted to investigate the effect of the number of prior surgeries $(0,1,2,3,4$, and 5 or more) and the presence of spinal instrumentation on outcomes. Multivariate analysis was used to adjust for relevant and significant confounders.
\end{abstract}

RESULTS A total of 300 patients were included; $38.3 \%$ of patients were male. The overall perioperative complication rate was $24.7 \%$, and the mean length of hospitalization was 8.2 days. The 90 -day readmission rate was $9.0 \%$, and the overall follow-up reoperation rate was $26.7 \%$. There were no significant differences in complication rates $(26.6 \%$ vs $24.0 \%, p=0.645$ ), length of hospitalization ( 8.7 vs 7.9 days, $p=0.229$ ), readmission rates $(11.4 \%$ vs $8.1 \%, p=0.387$ ), or reoperation rates $(26.6 \%$ vs $26.7 \%, p=0.984)$ between primary and revision cases. There was no significant difference in wound complications (infections/dehiscence) requiring reoperation ( $5.1 \%$ vs $6.3 \%, p=0.683)$. Subgroup analysis conducted to evaluate the effect of the number of prior spinal surgeries or the presence of spinal instrumentation did not reveal significant differences for the aforementioned surgical outcomes. In adjusted multivariate analysis, there were no significant associations between history of prior surgery (number of prior surgeries and prior instrumentation) and all of the surgical outcomes of interest.

CONCLUSIONS The findings from this study suggest that patients who have undergone prior spine surgery with or without instrumentation are not at increased risk for perioperative complications, need for readmission, or reoperation following 3-column osteotomy of the thoracolumbar spine.

https://thejns.org/doi/abs/10.3171/2017.8.FOCUS17460

KEY WORDS complications; 3-column osteotomy; prior surgery; spinal deformity

$\Lambda$ DULT spinal deformity (ASD) can result in sagittal and/or coronal imbalance, which is generally the result of asymmetrical degeneration of vertebral bodies, intervertebral discs, and facet joints.9 This progressive degenerative process can be hastened in the setting of concurrent spinal disease (chronic fractures and remote infection) or in patients with a history of prior spinal surgery with or without spinal instrumentation. Pa- tients with ASD typically present with debilitating axial back and neck pain, neurological deficits, and functional impairment (inability to complete activities of daily living and instrumental activities of daily living). ${ }^{9}$ In addition, patients with ASD present with poor self-esteem and personal dissatisfaction. ${ }^{8,10,14,19,22}$ The surgical correction of spinal imbalance can be effective in addressing the aforementioned problems in well-selected patients..$^{13,18,20}$ 
In patients with fixed, immobile thoracolumbar spinal deformities, 3-column osteotomies and long construct instrumented fusion are often warranted to achieve optimal correction and spinal balance. ${ }^{21}$ The morbidity associated with such intervention is not trivial, with major immediate perioperative complication rates estimated to be around $35 \%$ and an overall medical complication rate of approximately $50 \% .{ }^{1,2,11,24} \mathrm{Up}$ to $78 \%$ of patients who undergo 3 -column osteotomy require reoperation at the 1-year follow-up for rod fractures, wound breakdown, and proximal junctional kyphosis. ${ }^{26}$ There remains a need to understand which patients are at higher risk for the development of such complications in order to optimize outcomes.

Indeed, a number of patients who present with ASD have a history of prior spine surgery. Approximately half of ASD patients have undergone prior spine surgery with instrumentation in the area or in proximity to their spinal deformity, with a subset of patients having undergone multiple surgeries. The question that arises when we encounter patients who have undergone multiple surgeries and spinal fusions is whether these patients are at higher risk for complications. Some studies have suggested that patients who have undergone prior spine surgery may be at increased risk for postoperative complications, particularly issues with wound healing and infection..$^{4-6,12,23}$ Other studies have suggested that there are no differences in complication rates between primary and revision cases. ${ }^{716}$ However, some studies have revealed that primary surgeries may be associated with higher mortality and complication rates ${ }^{15,17}$ Furthermore, contemporary studies are needed to delineate the impact of revision surgery on rates of morbidity and postoperative complications. Moreover, studies that assess the impact of an incrementally greater number of prior surgeries, in a population that not uncommonly has more than a single prior operation, are necessary.

In this study, we evaluated whether any prior spinal surgery or spinal instrumentation is an independent risk factor for perioperative complications, 90-day readmission, and long-term reoperation in patients undergoing 3 -column osteotomy for thoracolumbar spinal deformity. We also performed a subgroup analysis, assessing the impact of an incrementally greater number of prior surgeries and the presence of spinal instrumentation on perioperative and follow-up outcomes.

\section{Methods}

This study was formally approved by the Committee of Human Research at the University of California, San Francisco.

\section{Patient Population}

A consecutive cohort of ASD patients ( $\geq 18$ years) who underwent a 3-column osteotomy for correction of thoracolumbar sagittal and/or coronal spinal deformity from January 2006 to July 2016 was identified. Patients with a diagnosis of infection/osteomyelitis, acute fractures, or tumors were excluded from the cohort. Indications for surgery were debilitating axial back or radicular pain that was not responsive to conservative management and/or neurological deficit in the setting of spinal deformity, causing abnormal sagittal and/or coronal imbalance. Threecolumn osteotomies included either pedicle subtraction osteotomies (PSOs) (Schwab $^{21}$ Grade 4 osteotomy) or vertebral column resections (VCRs) (Schwab Grades 5 and 6 osteotomy) via posterior approaches. All posterior approaches to fusion were performed through an open approach; no minimally invasive approaches were used among this cohort. Patients who underwent staged surgeries were included. Typically, patients who underwent a staged anterior/lateral procedure and subsequent posterior approach underwent their first- and second-stage surgeries over 2 consecutive days. The senior author, C.P.A., performed all of the surgeries, and V.D. was a cosurgeon for a majority of the cases.

\section{Study Variables}

The following patient demographic, clinical, and surgical variables were retrospectively collected: number of prior spinal surgeries within the spinal region of interest $(0,1,2,3,4$, and 5 or more), prior spinal instrumentation within the spinal region of interest, age $(<50,50-64,65-$ 79 , or $\geq 80$ years), sex (male or female), weight ( $<80$ or $\geq$ $80 \mathrm{~kg}$ ), type of 3-column osteotomy (PSO or VCR), level of osteotomy performed (thoracic, L-1, L-2, L-3, L-4, L-5, or S-1), number of levels instrumented ( $\leq 10$ or $>10$ ), upper instrumented level (upper thoracic or lower thoracic), and staged anterior/lateral procedure. Upper thoracic levels were defined as T-1, T-2, T-3, T-4, T-5, T-6, and T-7. Thoracolumbar junction levels were defined as T-8, T-9, T-10, T-11, T-12, L-1, and L-2. Comorbidities of interest included cardiac disease, hypertension, vascular disease, diabetes mellitus, pulmonary disease, renal disease, stroke/ transient ischemic attack, psychiatric disease, hyperlipidemia, and thyroid disease.

The primary outcomes of interest included perioperative complication, length of hospital stay, 90-day readmission, reoperation, and infectious complication. Perioperative complication was defined as any unexpected or unforeseen medical and/or surgical issue requiring additional intervention within the patient's hospital stay. The total length of stay was defined as the number of inpatient days from the date of first surgery to the date of discharge. Readmission was defined as admission to a hospital within 90 days of surgery, with the principal admission diagnosis judged as bearing relevance to the index surgery. Reoperation and infectious complications included events during both the perioperative period and postdischarge period (up until the latest clinical follow-up).

\section{Statistical Analysis}

First, a comparison of demographic and baseline variables was performed between primary and revision surgeries. Patients in the primary surgery group were individuals who had never undergone surgery in the spinal region of interest, and those in the revision group underwent any spinal surgery within the spinal region of interest (regardless of whether instrumentation was performed). Next, the outcomes of interest were compared between the 2 groups. Two-tailed chi-square tests and the Student t-test 
were performed for categorical and continuous variables, respectively. Multivariate analysis was performed to adjust for covariates that were significantly different from demographic and baseline clinical variables. Logistic regression and analysis of covariance were employed for categorical and continuous outcomes, respectively.

To further assess the independent relationship of number of prior surgeries to the outcomes of interest, multivariate models were built. First, basic descriptive statistics were performed to define the variables in relation to the outcomes of interest. Then, univariate statistics were employed to test significant associations between covariates and the outcomes of interest. The chi-square test was used for categorical outcomes. Next, multivariate analysis models were built to assess independent associations between covariates and the outcomes of interest. Prior surgery and covariates with $\mathrm{p}$ values $<0.200$ in the univariate analysis were included in the multivariate models. Multivariate logistic regression analysis was performed for categorical outcomes. A p value $<0.050$ was used as the threshold of statistical significance for this study. All statistics were performed using SAS software (version 9.4, SAS Institute).

\section{Results}

A total of 300 patients were included in the study. The mean age was 63.7 years, and $61.7 \%$ of patients were female. Seventy-nine patients $(26.3 \%)$ underwent primary surgery, and 221 (73.7\%) underwent revision. Among the revision patients, $114,52,31,15$, and 9 patients underwent $1,2,3,4$, and 5 or more prior surgeries, respectively. The majority of patients $(65.7 \%)$ had prior spinal instrumentation. Of the 300 patients, $17.3 \%$ underwent VCR, and the remaining patients underwent PSO. Osteotomies were performed in the thoracic spine (14.7\%) and at the L-1 (7.3\%), L-2 (7.0\%), L-3 (42.7\%), L-4 (24.7\%), L-5 (2.0\%), and S-1 $(1.7 \%)$ levels. More than half $(53.2 \%)$ of the patients had more than 10 instrumented levels, and upper instrumented vertebra occurred in the upper thoracic spine in $47.7 \%$ of cases. A 2-staged anterior/lateral-posterior approach was performed in $20.3 \%$ of cases.

\section{Comparison of Outcomes Between Primary and Revision Patients}

Table 1 compares demographics and baseline clinical variables between primary and revision cases. Primary surgery patients underwent VCR more frequently than revision surgery patients $(35.4 \%$ vs $10.9 \%, \mathrm{p}<0.001)$, and therefore more osteotomies were performed in the thoracic spine $(29.1 \%$ vs $9.5 \%$, p < 0.001$)$. There were no significant differences between other covariates.

Table 2 compares perioperative and follow-up outcomes of interest between primary and revision surgery patients. Outcomes were adjusted for osteotomy type and level. The overall perioperative complication rate was $24.7 \%$, and the mean length of stay was 8.2 days. Between primary and revision cases, there were no significant differences in complication rate $(26.6 \%$ vs $24.0 \%, \mathrm{p}=0.450)$ and length of stay ( 8.7 vs 7.9 days, $\mathrm{p}=0.226$ ). Overall, the 90-day readmission rate was $9.0 \%$, and both groups had similar 90 -day readmission rates $(11.4 \%$ vs $8.1 \%, \mathrm{p}=0.383)$. The
TABLE 1. Comparison of demographics, baseline clinical variables, and operative details between primary surgery and revision surgery patients

\begin{tabular}{|c|c|c|c|}
\hline \multirow[b]{2}{*}{ Variable } & \multicolumn{2}{|c|}{ No. of Patients (\%) } & \multirow[b]{2}{*}{$p$ Value } \\
\hline & $\begin{array}{l}\text { Primary } \\
(n=79)\end{array}$ & $\begin{array}{l}\text { Revision } \\
(n=221)\end{array}$ & \\
\hline Age in yrs & & & 0.063 \\
\hline$<50$ & $11(13.9)$ & $20(9.1)$ & \\
\hline $50-64$ & $26(32.9)$ & $82(37.1)$ & \\
\hline $65-79$ & $31(39.2)$ & $106(48.0)$ & \\
\hline$\geq 80$ & $11(13.9)$ & $13(5.9)$ & \\
\hline Sex & & & 0.847 \\
\hline Male & $31(39.2)$ & $84(38.0)$ & \\
\hline Female & $48(60.8)$ & $137(62.0)$ & \\
\hline Weight in $\mathrm{kg}$ & & & 0.081 \\
\hline$<80$ & $48(60.8)$ & $109(49.3)$ & \\
\hline$\geq 80$ & $31(39.2)$ & $112(50.7)$ & \\
\hline 3-column osteotomy type & & & $<0.001$ \\
\hline VCR & $28(35.4)$ & $24(10.9)$ & \\
\hline PSO & $51(64.6)$ & $197(89.1)$ & \\
\hline Osteotomy level & & & $<0.001$ \\
\hline Thoracic & $23(29.1)$ & $21(9.5)$ & \\
\hline$L-1$ & $10(12.7)$ & $12(5.4)$ & \\
\hline $\mathrm{L}-2$ & $6(7.6)$ & $15(6.8)$ & \\
\hline L-3 & $25(31.7)$ & $103(46.6)$ & \\
\hline $\mathrm{L}-4$ & $12(15.2)$ & $62(28.1)$ & \\
\hline$L-5$ & $2(2.5)$ & $4(1.8)$ & \\
\hline S-1 & $1(1.3)$ & $4(1.8)$ & \\
\hline Instrumented levels & & & 0.918 \\
\hline$\leq 10$ & $37(46.8)$ & $42(53.2)$ & \\
\hline$>10$ & $42(53.2)$ & $116(52.5)$ & \\
\hline UIV & & & 0.096 \\
\hline Upper thoracic & $44(55.7)$ & $99(44.8)$ & \\
\hline Lower thoracic & $35(44.3)$ & $122(55.2)$ & \\
\hline 2-stage anterior-posterior & & & 0.099 \\
\hline Yes & $11(13.9)$ & $50(22.6)$ & \\
\hline No & $68(86.1)$ & $171(77.4)$ & \\
\hline \multicolumn{4}{|l|}{ Comorbidities } \\
\hline Cardiac disease & $17(21.5)$ & $51(23.1)$ & 0.777 \\
\hline Hypertension & $39(49.4)$ & $129(58.4)$ & 0.166 \\
\hline Vascular disease & $7(8.9)$ & $12(5.4)$ & 0.283 \\
\hline Diabetes & $8(10.1)$ & $38(17.2)$ & 0.135 \\
\hline Pulmonary disease & $15(19.0)$ & 40 (18.1) & 0.861 \\
\hline Renal disease & $6(7.6)$ & $14(6.3)$ & 0.700 \\
\hline Stroke/TIA & $4(5.1)$ & $9(4.1)$ & 0.710 \\
\hline Psychiatric disease & $15(19.0)$ & $53(24.0)$ & 0.363 \\
\hline Hyperlipidemia & $12(15.2)$ & $53(24.0)$ & 0.104 \\
\hline Thyroid disease & $11(13.9)$ & $30(13.6)$ & 0.938 \\
\hline
\end{tabular}

$\mathrm{TIA}=$ transient ischemic attack; UIV = upper instrumented vertebra. 
TABLE 2. Comparison of outcomes between primary and revision surgeries

\begin{tabular}{|c|c|c|c|c|c|}
\hline \multirow[b]{2}{*}{ Outcome } & \multirow[b]{2}{*}{ Overall $(n=300)$} & \multirow[b]{2}{*}{ Primary $(n=79)$} & \multirow{2}{*}{$\begin{array}{l}\text { Revision } \\
(n=221)\end{array}$} & \multicolumn{2}{|c|}{$p$ Value } \\
\hline & & & & Univariate & Multivariate* \\
\hline Periop complications & $74(24.7)$ & $21(26.6)$ & $53(24.0)$ & 0.645 & 0.450 \\
\hline LOS in days, mean \pm SD & $8.2 \pm 4.9$ & $8.7 \pm 6.0$ & $7.9 \pm 4.5$ & 0.229 & 0.226 \\
\hline Readmission & $27(9.0)$ & $9(11.4)$ & $18(8.1)$ & 0.387 & 0.383 \\
\hline Reop & $80(26.7)$ & $21(26.6)$ & $59(26.7)$ & 0.984 & 0.894 \\
\hline Reop for infection & $18(6.0)$ & $4(5.1)$ & $14(6.3)$ & 0.683 & 0.985 \\
\hline
\end{tabular}

reasons for readmission were pleural empyema requiring chest tubes, lower-extremity weakness secondary to hematoma, ventriculitis, urinary tract infection, ileus, pulmonary embolus, pain, wound dehiscence requiring revision, and wound infection requiring washout. The reoperation rate was $26.7 \%$, and the specific reoperation rate for infection and wound issues was $6.0 \%$. There were no significant differences in the overall follow-up reoperation rate (26.6\% vs $26.7 \%, p=0.894)$. The most common diagnoses for those requiring reoperations were pseudarthrosis, implant failure, junctional kyphosis, and wound infections. The reoperation rates for infection were comparable between the 2 groups $(5.1 \%$ vs $6.3 \%, p=0.985)$.

\section{Number of Prior Surgeries and Relationship to Outcomes}

Table 3 shows the results of univariate analysis of various covariates and the outcomes of interest. Among the 300 patients, 221 (73.7\%) underwent revision surgery and 197 (65.7\%) had prior spinal instrumentation. There was no significant association between number of prior surgeries and all measured outcomes: complication $(p=0.892)$, 90 -day readmission $(\mathrm{p}=0.468)$, reoperation $(\mathrm{p}=0.509)$, and infection requiring reoperation $(\mathrm{p}=0.382)$. Similarly, there was no significant difference in outcomes when assessing the relationship of prior instrumentation and outcomes of interest: complications ( $\mathrm{p}=0.465), 90$-day readmission $(\mathrm{p}=0.462)$, reoperation $(\mathrm{p}=0.687)$, and infection requiring reoperation $(\mathrm{p}=0.546)$ (Table 3$)$.

Table 4 shows the results of the multivariate analysis, adjusting for potential confounders, evaluating the independent relationship of prior surgical history to the outcomes of interest. Relative to primary cases, prior surgery (regardless of the number of surgeries) was not an independent factor for perioperative complication, 90-day readmission, reoperation, or infection. Similarly, prior spinal instrumentation was also not a risk factor for all outcomes. Rather, independent factors associated with worse outcomes were the presence of baseline renal disease (OR for perioperative complication 5.82, 95\% CI 1.96-17.27, $\mathrm{p}=0.002)$ and a comorbid psychiatric diagnosis (OR for 90 -day readmission $2.70,95 \%$ CI $1.08-6.76, \mathrm{p}=0.033$ ).

\section{Discussion}

Many ASD patients have undergone prior spine surgery and spinal instrumentation. In this cohort, a majority of patients $(73.7 \%)$ had undergone prior surgery, and more than half of the patients $(65.7 \%)$ had prior spinal instrumentation. In fact, $35.6 \%$ of patients had undergone multiple (at least 2) surgeries prior to presenting. It would be intuitive that a prior surgical history and more prior surgeries (revisions) would place patients at higher risk for complications, particularly wound healing issues and infections. However, in this contemporary cohort of patients who underwent 3-column osteotomy and long construct spinal fixation, the findings suggest otherwise, demonstrating similar perioperative and follow-up outcomes between primary and revision cases. Prior surgery also was not independently associated with any of the outcomes of interest. This is consistent with a prior study showing that revision surgery patients benefited equally from surgery as primary surgery patients at 2-year follow-up?

Complication rates following 3-column osteotomy are relatively high, reflecting the technically demanding nature of the procedure. Reported intraoperative complication rates are estimated to be around $7 \%$, and new neurological deficits are observed in approximately 7\%-10\% of cases. ${ }^{3,11}$ Overall perioperative complication rates have been reported to range from $39 \%$ to $61 \% .3,11,24,25$ In regard to revision cases, the literature has conflicting evidence on the incidence of complication rates and morbidity.

According to several prior studies, revision cases are associated with higher complication rates. In a study of 10,912 patients from the National (Nationwide) Inpatient Sample (NIS) database who underwent all types of spinal fusions, the incidence of procedure-related complications was approximately $30 \%$ higher for patients who underwent revision surgery than for primary cases. ${ }^{6}$ This study also suggested that patients undergoing revision surgery are at specific increased risk of complications involving the nervous system, hematoma formation, vascular injury, nerve puncture, wound dehiscence, infection, and acute respiratory distress syndrome. ${ }^{6}$ Similarly, in a study of ASD patients who underwent surgery for adult scoliosis, revision patients were found to have a higher overall complication rate than primary patients ( $58.2 \%$ vs $45.2 \%$, respectively). ${ }^{5}$

Results from other studies have suggested that there are no differences in morbidity and complication risk between primary and revision surgeries. Linville et al. performed a small retrospective study in which they compared the complications of 18 primary surgery and 26 revision sur- 
TABLE 3. Univariate associations between prior surgical history and perioperative and follow-up outcomes

\begin{tabular}{|c|c|c|c|c|c|c|c|c|c|}
\hline \multirow[b]{2}{*}{ Variable } & \multirow{2}{*}{$\begin{array}{c}\text { Overall No. } \\
\text { of Patients } \\
(\%)\end{array}$} & \multicolumn{2}{|c|}{ Complications } & \multicolumn{2}{|c|}{ Readmission } & \multicolumn{2}{|c|}{ Reop } & \multicolumn{2}{|c|}{ Reop for Infection } \\
\hline & & $\begin{array}{c}\text { No. of } \\
\text { Patients (\%) }\end{array}$ & $\begin{array}{c}p \\
\text { Value }\end{array}$ & $\begin{array}{c}\text { No. of } \\
\text { Patients (\%) }\end{array}$ & $\begin{array}{c}p \\
\text { Value }\end{array}$ & $\begin{array}{c}\text { No. of } \\
\text { Patients (\%) }\end{array}$ & $\begin{array}{c}p \\
\text { Value }\end{array}$ & $\begin{array}{c}\text { No. of } \\
\text { Patients (\%) }\end{array}$ & $\begin{array}{c}p \\
\text { Value }\end{array}$ \\
\hline Total & 300 & $74(24.7)$ & & $27(9.0)$ & & $80(26.7)$ & & $18(6.0)$ & \\
\hline No. of prior ops & & & 0.892 & & 0.468 & & 0.509 & & 0.382 \\
\hline 0 & $79(26.3)$ & $21(26.6)$ & & $9(11.4)$ & & $21(26.6)$ & & $4(5.1)$ & \\
\hline 1 & $114(38.0)$ & $24(21.1)$ & & $9(7.9)$ & & $34(29.8)$ & & $6(5.3)$ & \\
\hline 2 & $52(17.3)$ & $13(25.0)$ & & $6(11.5)$ & & $12(23.1)$ & & $2(3.8)$ & \\
\hline 3 & $31(10.3)$ & $9(29.0)$ & & $0(0.0)$ & & $9(29.0)$ & & $4(12.9)$ & \\
\hline 4 & $15(5.0)$ & $4(26.7)$ & & $2(13.3)$ & & $4(26.7)$ & & $2(13.3)$ & \\
\hline$\geq 5$ & $9(3.0)$ & $3(33.3)$ & & $1(11.1)$ & & $0(0.0)$ & & $0(0.0)$ & \\
\hline Prior instrumentation/fusion & & & 0.465 & & 0.462 & & 0.687 & & 0.546 \\
\hline Yes & $197(65.7)$ & $46(23.4)$ & & $16(8.1)$ & & $48(24.4)$ & & $13(6.6)$ & \\
\hline No & $103(34.3)$ & $28(27.2)$ & & $11(10.7)$ & & $23(22.3)$ & & $5(4.9)$ & \\
\hline Age in yrs & & & 0.002 & & 0.078 & & 0.832 & & 0.461 \\
\hline$<50$ & $31(10.3)$ & $3(9.7)$ & & $0(0.0)$ & & $7(22.6)$ & & $0(0.0)$ & \\
\hline $50-64$ & $108(36.0)$ & $18(16.7)$ & & $7(6.5)$ & & $32(29.6)$ & & $8(7.4)$ & \\
\hline $65-79$ & $137(45.7)$ & $43(31.4)$ & & $16(11.7)$ & & $35(25.5)$ & & $9(6.6)$ & \\
\hline$\geq 80$ & $24(8.0)$ & $10(41.7)$ & & $4(16.7)$ & & $6(25.0)$ & & $1(4.2)$ & \\
\hline Sex & & & 0.468 & & 0.026 & & 0.128 & & 0.960 \\
\hline Male & $115(38.3)$ & $31(27.0)$ & & $5(4.3)$ & & $25(21.7)$ & & $7(6.1)$ & \\
\hline Female & $185(61.7)$ & $43(23.2)$ & & $22(11.9)$ & & $55(29.7)$ & & $11(5.9)$ & \\
\hline Weight in $\mathrm{kg}$ & & & 0.846 & & 0.038 & & 0.821 & & 0.239 \\
\hline$<80$ & $157(52.3)$ & $38(24.2)$ & & $9(5.7)$ & & $41(26.1)$ & & $7(4.5)$ & \\
\hline$\geq 80$ & $143(47.7)$ & $36(25.2)$ & & $18(12.6)$ & & $39(27.3)$ & & $11(7.7)$ & \\
\hline 3-column osteotomy type & & & 0.951 & & 0.482 & & 0.323 & & 0.472 \\
\hline VCR & $52(17.3)$ & $13(25.0)$ & & $6(11.5)$ & & $11(21.2)$ & & $2(3.8)$ & \\
\hline PSO & $248(82.7)$ & $61(24.6)$ & & $21(8.5)$ & & $69(27.8)$ & & $16(6.5)$ & \\
\hline Osteotomy level & & & 0.054 & & 0.829 & & 0.972 & & 0.552 \\
\hline Thoracic & $44(14.7)$ & $8(18.2)$ & & $4(9.1)$ & & $12(27.3)$ & & $2(4.5)$ & \\
\hline$L-1$ & $22(7.3)$ & $5(22.7)$ & & $2(9.1)$ & & $6(27.3)$ & & $0(0.0)$ & \\
\hline $\mathrm{L}-2$ & $21(7.0)$ & $8(38.1)$ & & $1(4.8)$ & & 7 (33.3) & & $0(0.0)$ & \\
\hline$L-3$ & $128(42.7)$ & $24(18.8)$ & & $14(10.9)$ & & $32(25.0)$ & & $10(7.8)$ & \\
\hline$L-4$ & $74(24.7)$ & $25(33.8)$ & & $5(6.8)$ & & $19(25.7)$ & & $6(8.1)$ & \\
\hline$L-5$ & $6(2.0)$ & $1(16.7)$ & & $0(0.0)$ & & $2(33.3)$ & & $0(0.0)$ & \\
\hline S-1 & $5(1.7)$ & $3(60.0)$ & & $1(20.0)$ & & $2(40.0)$ & & $0(0.0)$ & \\
\hline Instrumented levels & & & 0.106 & & 0.472 & & 0.767 & & 0.227 \\
\hline$\leq 10$ & $142(47.3)$ & $29(20.4)$ & & $11(7.7)$ & & $39(27.5)$ & & $11(7.7)$ & \\
\hline$>10$ & $158(52.7)$ & $45(28.5)$ & & $16(10.1)$ & & $41(25.9)$ & & $7(4.4)$ & \\
\hline UIV & & & 0.643 & & 0.958 & & 0.972 & & 0.209 \\
\hline Upper thoracic & $143(47.7)$ & $37(25.9)$ & & $14(9.8)$ & & $42(29.4)$ & & $6(4.2)$ & \\
\hline Lower thoracic & $157(52.3)$ & $37(23.6)$ & & $13(8.3)$ & & $38(24.2)$ & & $12(7.6)$ & \\
\hline 2-stage anterior-posterior & & & 0.311 & & 0.024 & & 0.067 & & 0.690 \\
\hline Yes & $61(20.3)$ & $12(19.7)$ & & $1(1.6)$ & & $9(14.8)$ & & $3(4.9)$ & \\
\hline No & $239(79.7)$ & $62(25.9)$ & & $26(10.9)$ & & $62(25.9)$ & & $15(6.3)$ & \\
\hline \multicolumn{10}{|l|}{ Comorbidities } \\
\hline Cardiac disease & & & 0.021 & & 0.701 & & 0.497 & & 0.227 \\
\hline Yes & $68(22.7)$ & $24(35.3)$ & & $3(4.4)$ & & $14(20.6)$ & & $2(2.9)$ & \\
\hline No & $232(77.3)$ & $50(21.6)$ & & $13(5.6)$ & & $57(24.6)$ & & $16(6.9)$ & \\
\hline
\end{tabular}


TABLE 3. Univariate associations between prior surgical history and perioperative and follow-up outcomes

\begin{tabular}{|c|c|c|c|c|c|c|c|c|c|}
\hline \multirow[b]{2}{*}{ Variable } & \multirow{2}{*}{$\begin{array}{c}\text { Overall No. } \\
\text { of Patients } \\
\quad(\%)\end{array}$} & \multicolumn{2}{|c|}{ Complications } & \multicolumn{2}{|c|}{ Readmission } & \multicolumn{2}{|c|}{ Reop } & \multicolumn{2}{|c|}{ Reop for Infection } \\
\hline & & $\begin{array}{c}\text { No. of } \\
\text { Patients (\%) }\end{array}$ & $\begin{array}{c}p \\
\text { Value }\end{array}$ & $\begin{array}{c}\text { No. of } \\
\text { Patients (\%) }\end{array}$ & $\begin{array}{c}p \\
\text { Value }\end{array}$ & $\begin{array}{c}\text { No. of } \\
\text { Patients (\%) }\end{array}$ & $\begin{array}{c}p \\
\text { Value }\end{array}$ & $\begin{array}{c}\text { No. of } \\
\text { Patients (\%) }\end{array}$ & $\begin{array}{c}p \\
\text { Value }\end{array}$ \\
\hline \multicolumn{10}{|c|}{ Comorbidities (continued) } \\
\hline Hypertension & & & 0.010 & & 0.291 & & 0.450 & & 0.597 \\
\hline Yes & $168(56.0)$ & $51(30.4)$ & & $11(6.5)$ & & $37(22.0)$ & & $9(5.4)$ & \\
\hline No & $132(44.0)$ & $23(17.4)$ & & $5(3.8)$ & & $34(25.8)$ & & $9(6.8)$ & \\
\hline Vascular disease & & & 0.470 & & 0.298 & & 0.163 & & 0.889 \\
\hline Yes & $19(6.3)$ & $6(31.6)$ & & $2(10.5)$ & & $7(36.8)$ & & $1(5.3)$ & \\
\hline No & $281(93.7)$ & $68(24.2)$ & & $14(5.0)$ & & $64(22.8)$ & & $17(6.0)$ & \\
\hline Diabetes & & & 0.383 & & 0.697 & & 0.738 & & 0.871 \\
\hline Yes & $46(15.3)$ & $9(19.6)$ & & $3(6.5)$ & & $10(21.7)$ & & $3(6.5)$ & \\
\hline No & $254(84.7)$ & $65(25.6)$ & & $13(5.1)$ & & $61(24.0)$ & & $15(5.9)$ & \\
\hline Pulmonary disease & & & 0.400 & & 0.965 & & 0.730 & & 0.851 \\
\hline Yes & $55(18.3)$ & $16(29.1)$ & & $3(5.5)$ & & $14(25.5)$ & & $3(5.5)$ & \\
\hline No & $245(81.7)$ & $58(23.7)$ & & $13(5.3)$ & & $57(23.3)$ & & $15(6.1)$ & \\
\hline Renal disease & & & $<0.001$ & & 0.046 & & 0.690 & & 0.846 \\
\hline Yes & $20(6.7)$ & $14(70.0)$ & & $3(15.0)$ & & $4(20.0)$ & & $1(5.0)$ & \\
\hline No & $280(93.3)$ & $60(21.4)$ & & $13(4.6)$ & & $67(23.9)$ & & $17(6.1)$ & \\
\hline Stroke/TIA & & & 0.066 & & 0.699 & & 0.040 & & 0.793 \\
\hline Yes & $13(4.3)$ & $6(46.2)$ & & $1(7.7)$ & & $0(0.0)$ & & $0(0.0)$ & \\
\hline No & $287(95.7)$ & $68(23.7)$ & & $15(5.2)$ & & $71(24.7)$ & & $1(0.3)$ & \\
\hline Psychiatric disease & & & 0.476 & & 0.145 & & 0.536 & & 0.531 \\
\hline Yes & $68(22.7)$ & $19(27.9)$ & & $6(8.8)$ & & $18(26.5)$ & & $3(4.4)$ & \\
\hline No & $232(77.3)$ & $55(23.7)$ & & $10(4.3)$ & & $53(22.8)$ & & $15(6.5)$ & \\
\hline Hyperlipidemia & & & 0.106 & & 0.114 & & 0.594 & & 0.215 \\
\hline Yes & $65(21.7)$ & $21(32.3)$ & & $6(9.2)$ & & $17(26.2)$ & & $6(9.2)$ & \\
\hline No & $235(78.3)$ & $53(22.6)$ & & $10(4.3)$ & & $54(23.0)$ & & $12(5.1)$ & \\
\hline Thyroid disease & & & 0.057 & & 0.375 & & 0.907 & & 0.276 \\
\hline Yes & $41(13.7)$ & $15(36.6)$ & & $1(2.4)$ & & $10(24.4)$ & & $4(9.8)$ & \\
\hline No & $259(86.3)$ & $59(22.8)$ & & $15(5.8)$ & & $61(23.6)$ & & $14(5.4)$ & \\
\hline
\end{tabular}

gery patients who underwent combined anterior-posterior surgery for ASD. ${ }^{16}$ At the 6-month follow-up, similar complication rates and profiles were observed between the 2 groups (major [11.1\% vs $7.8 \%$ ] and minor [11.1\% vs $11.5 \%]$ complications). Fu et al. performed a study assessing complications between 53 primary surgery and 31 revision surgery patients who underwent surgery for degenerative scoliosis. ${ }^{7}$ They examined in detail the specific complications encountered, and despite greater case complexity in the revision group (greater preoperative coronal imbalance), they did not observe significant differences in complication rates. Specifically, there were similar rates of superficial infection $(0.0 \%$ vs $3.2 \%$ ), deep infection $(5.7 \%$ vs $6.5 \%)$, pseudarthrosis $(23.2 \%$ vs $0.0 \%)$, and reoperation $(18.9 \%$ vs $25.8 \%$ ). Of note, the deep infection and reoperation rates are similar to the findings in our study. The main criticism of these studies is that they may be underpowered to detect differences of specific complications between the cohorts.

Perhaps most surprisingly, there are also studies re- porting worse perioperative and long-term outcomes in primary cases than in revision cases, although the data to support this finding are limited. A study by Ma et al. used the NIS and compared in-hospital mortality rates of 222,549 primary and 12,474 revision thoracic and/or lumbar fusion surgeries. ${ }^{17}$ Their findings showed a small but significantly higher mortality rate in primary cases than in revision cases $(0.28 \%$ vs $0.15 \%)$. With regard to long-term outcomes, there are data to suggest that primary cases are associated with a higher rate of major complications, especially pseudarthrosis, at the 2-year follow-up. ${ }^{15}$

The inconsistent findings regarding the morbidity of primary versus revision spinal surgery are likely a result of various confounding factors (not adjusted or controlled for in the available studies and literature). Some studies compare revision and primary cases regardless of specific surgical approaches and procedures performed. For example, Diebo et al. compared revision cases of patients who underwent combined anterior-posterior fusion with 
TABLE 4. Multivariate analysis testing for independent associations to perioperative and follow-up outcomes

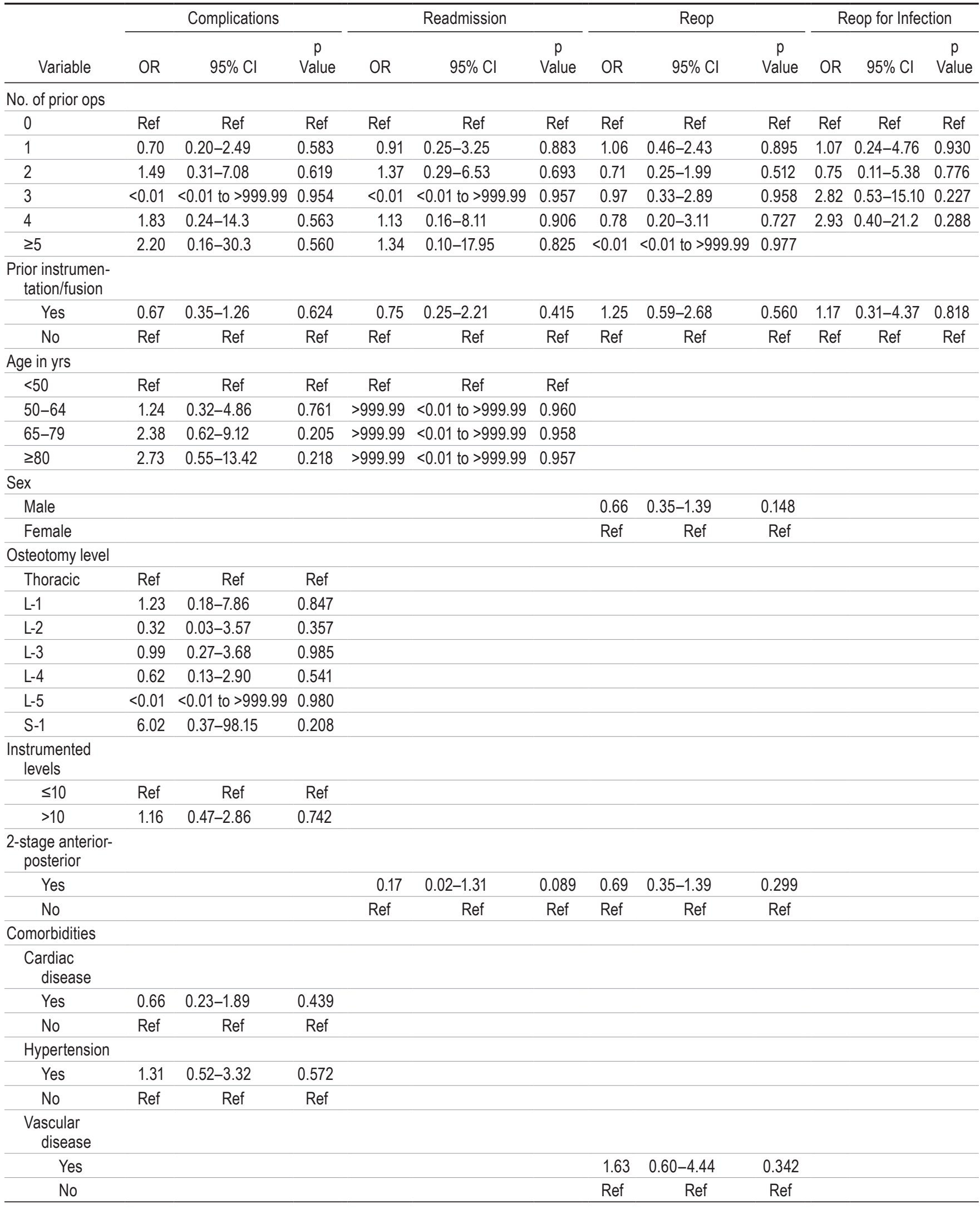


TABLE 4. Multivariate analysis testing for independent associations to perioperative and follow-up outcomes

\begin{tabular}{|c|c|c|c|c|c|c|c|c|c|c|c|c|}
\hline \multirow[b]{2}{*}{ Variable } & \multicolumn{3}{|c|}{ Complications } & \multicolumn{3}{|c|}{ Readmission } & \multicolumn{3}{|c|}{ Reop } & \multicolumn{3}{|c|}{ Reop for Infection } \\
\hline & OR & $95 \% \mathrm{Cl}$ & $\begin{array}{c}p \\
\text { Value }\end{array}$ & OR & $95 \% \mathrm{Cl}$ & $\begin{array}{c}p \\
\text { Value }\end{array}$ & OR & $95 \% \mathrm{Cl}$ & $\begin{array}{c}p \\
\text { Value }\end{array}$ & OR & $95 \% \mathrm{Cl}$ & $\begin{array}{c}p \\
\text { Value }\end{array}$ \\
\hline \multicolumn{13}{|l|}{$\begin{array}{r}\text { Comorbidities } \\
\text { (continued) }\end{array}$} \\
\hline \multicolumn{13}{|c|}{ Renal disease } \\
\hline Yes & 5.82 & $1.96-17.27$ & 0.002 & 1.29 & $0.35-4.71$ & 0.701 & & & & & & \\
\hline No & Ref & Ref & Ref & Ref & Ref & Ref & & & & & & \\
\hline \multicolumn{13}{|c|}{ Stroke/TIA } \\
\hline Yes & 0.66 & $0.08-5.75$ & 0.706 & & & & 0.23 & $0.03-1.81$ & 0.161 & & & \\
\hline No & Ref & Ref & Ref & & & & Ref & Ref & Ref & & & \\
\hline \multicolumn{13}{|l|}{$\begin{array}{c}\text { Psychiatric } \\
\text { disease }\end{array}$} \\
\hline Yes & & & & 2.70 & $1.08-6.76$ & 0.033 & & & & & & \\
\hline No & & & & Ref & Ref & Ref & & & & & & \\
\hline \multicolumn{13}{|l|}{$\begin{array}{l}\text { Hyperlipid- } \\
\text { emia }\end{array}$} \\
\hline Yes & 1.61 & $0.61-4.24$ & 0.336 & 1.60 & $0.62-4.13$ & 0.327 & & & & & & \\
\hline No & Ref & Ref & Ref & Ref & Ref & Ref & & & & & & \\
\hline \multicolumn{13}{|l|}{$\begin{array}{l}\text { Thyroid } \\
\text { disease }\end{array}$} \\
\hline Yes & 0.90 & $0.26-3.11$ & 0.867 & & & & & & & & & \\
\hline No & Ref & Ref & Ref & & & & & & & & & \\
\hline
\end{tabular}

Ref $=$ reference.

primary surgery patients who underwent single-stage posterior spinal fusion. ${ }^{6}$ In addition, variables such as comorbidities, nutritional status, age, and frailty are likely significant contributors to morbidity and are not consistently included in past studies. However, even when authors attempt to concentrate on a homogeneous cohort of patients, the data among different independent studies remain inconclusive. Chang et al. performed a retrospective study comparing outcomes of primary and revision surgeries in patients older than 75 years. ${ }^{4}$ They found a trend for a slightly higher complication rate in revision cases than in primary cases at the 2-year follow-up. To this point, Cho et al. compared complication rates between 126 primary and 124 revision patients who underwent adult scoliosis surgery and found an overall higher complication rate in revision cases. ${ }^{5}$ However, when stratified by age, complication rates were similar in patients older than 60 years. With regard to other confounding parameters (such as comorbidities and type of surgery), Kurtz et al. performed a multivariate analysis comparing superficial and deep infectious complications between primary and revision surgery patients who underwent lumbar instrumentation and fusion. ${ }^{12}$ Their cohort was generated from the Medicare database and consisted of 15,069 primary and 605 revision cases. They found a $3.7 \%$ higher rate of infection over a 10 -year period for revision cases. However, the greatest predictors of wound infection were the number of comorbidities and number of levels fused. Therefore, careful consideration of baseline demographics and details of the operative course needs to be given when comparing outcomes of primary and revision patients.

It is important to note that complication rates and profiles for primary and revision cases are likely not generalizable to all spine cases because of the different approaches taken (open vs minimally invasive) and pathologies (treated deformity, degenerative, vs tumors). Comparisons of morbidity between primary and revision cases should be done in patients undergoing similar surgeries for the same etiologies. We studied a cohort of patients who underwent posterior approaches to thoracolumbar 3-column osteotomy for ASD by a single surgeon. In this specific population of patients, outcomes were similar between the primary and revision groups. An example in which revision cases have clearly proven to be more difficult and associated with higher complication rates is during same-level anterior lumbar spine revisions. ${ }^{23}$ The reported complication rates in revision cases are 3-5 times higher than in primary cases. In revision cases, reoperation of the same level is associated with a much higher incidence of vein lacerations due to scarring (23.7\% vs $3.6 \%$ ). When counseling patients who have undergone prior surgery, it is important to take into account the specific procedure being performed.

Our study has limitations because of its retrospective design and the presence of small sample sizes in particular subgroups. Retrospective studies are at risk for nonrandom distribution of baseline variables. For example, the primary cohort had a disproportionately higher number of VCR and osteotomies than the revision cohort at the tho- 
racic level. However, we adjusted for these differences in a multivariate analysis. In our study, similar complication and outcome profiles were observed in patients who had undergone any number of prior surgeries with or without spinal instrumentation compared with primary patients. In fact, our data suggest that the number of surgeries was not an independent factor associated with higher odds of worse outcome. This may not be intuitive, given that each time a patient undergoes surgery, his or her skin, soft tissue, paraspinal musculature, and fascia are devascularized, injured, and eventually result in scar tissue. Experience may lead one to assume that there may be a higher risk of wound healing issues and infections. Indeed, while our analysis did not reach statistical significance, there was a trend for increased odds of complications (0.70-2.20) and infections (1.07-2.93) when comparing primary surgery patients with patients who had undergone 5 or more prior surgeries. The reason for not detecting such differences might be due to the small subgroups of patients who underwent 4 surgeries and 5 or more prior surgeries; only 24 of the 300 patients underwent 4 or more prior surgeries. The statistical power in other subgroups remains strong, and based on these findings, it is evident that patients who underwent $0-3$ prior surgeries have similar morbidity and outcome profiles.

\section{Conclusions}

Many patients who present with ASD have undergone prior spine surgery. A subset may have undergone multiple prior surgeries with or without spinal instrumentation. Results from prior studies regarding whether revision cases are associated with a higher risk of complications, reoperation, and infection are inconsistent. According to the present study, primary and revision cases have similar rates of complication, 90-day readmission, reoperation, and wound infection for ASD patients undergoing thoracolumbar 3-column osteotomy. An increasing number of prior surgeries and history of prior spinal instrumentation were not significant risk factors for inferior outcomes. The present data are relevant to patients undergoing 3-column osteotomies for ASD; more studies are required to evaluate whether these results hold true for specific procedure types and treatment of other pathological processes. It is also important to appreciate that the findings from this study are based on outcomes from very experienced spinal deformity surgeons who have a high-volume 3-column osteotomy practice. It is possible that for less experienced surgeons, revision and primary cases may be associated with different outcomes. Additional studies are warranted.

\section{References}

1. Auerbach JD, Lenke LG, Bridwell KH, Sehn JK, Milby $\mathrm{AH}$, Bumpass D, et al: Major complications and comparison between 3-column osteotomy techniques in 105 consecutive spinal deformity procedures. Spine (Phila Pa 1976) 37:1198-1210, 2012

2. Baldus CR, Bridwell KH, Lenke LG, Okubadejo GO: Can we safely reduce blood loss during lumbar pedicle subtraction osteotomy procedures using tranexamic acid or aprotinin? A comparative study with controls. Spine (Phila Pa 1976) 35:235-239, 2010
3. Bianco K, Norton R, Schwab F, Smith JS, Klineberg E, Obeid I, et al: Complications and intercenter variability of threecolumn osteotomies for spinal deformity surgery: a retrospective review of 423 patients. Neurosurg Focus 36(5):E18, 2014

4. Chang MS, Chang YH, Revella J, Crandall DG: Revision spinal fusion in patients older than 75: is it worth the risks? Spine (Phila Pa 1976) 39:E35-E39, 2014

5. Cho SK, Bridwell KH, Lenke LG, Cho W, Zebala LP, Pahys $\mathrm{JM}$, et al: Comparative analysis of clinical outcome and complications in primary versus revision adult scoliosis surgery. Spine (Phila Pa 1976) 37:393-401, 2012

6. Diebo BG, Passias PG, Marascalchi BJ, Jalai CM, Worley NJ, Errico TJ, et al: Primary versus revision surgery in the setting of adult spinal deformity: a nationwide study on 10,912 patients. Spine (Phila Pa 1976) 40:1674-1680, 2015

7. Fu L, Chang MS, Crandall DG, Revella J: Comparative analysis of clinical outcomes and complications in patients with degenerative scoliosis undergoing primary versus revision surgery. Spine (Phila Pa 1976) 39:805-811, 2014

8. Glassman SD, Berven S, Bridwell K, Horton W, Dimar JR: Correlation of radiographic parameters and clinical symptoms in adult scoliosis. Spine (Phila Pa 1976) 30:682-688, 2005

9. Good CR, Auerbach JD, O'Leary PT, Schuler TC: Adult spine deformity. Curr Rev Musculoskelet Med 4:159-167, 2011

10. Harroud A, Labelle H, Joncas J, Mac-Thiong JM: Global sagittal alignment and health-related quality of life in lumbosacral spondylolisthesis. Eur Spine J 22:849-856, 2013

11. Kelly MP, Lenke LG, Shaffrey CI, Ames CP, Carreon LY, Lafage V, et al: Evaluation of complications and neurological deficits with three-column spine reconstructions for complex spinal deformity: a retrospective Scoli-RISK-1 study. Neurosurg Focus 36(5):E17, 2014

12. Kurtz SM, Lau E, Ong KL, Carreon L, Watson H, Albert T, et al: Infection risk for primary and revision instrumented lumbar spine fusion in the Medicare population. J Neurosurg Spine 17:342-347, 2012

13. Lafage R, Schwab F, Challier V, Henry JK, Gum J, Smith J, et al: Defining spino-pelvic alignment thresholds: should operative goals in adult spinal deformity surgery account for age? Spine (Phila Pa 1976) 41:62-68, 2016

14. Lafage V, Schwab F, Patel A, Hawkinson N, Farcy JP: Pelvic tilt and truncal inclination: two key radiographic parameters in the setting of adults with spinal deformity. Spine (Phila Pa 1976) 34:E599-E606, 2009

15. Lapp MA, Bridwell KH, Lenke LG, Daniel Riew K, Linville DA, Eck KR, et al: Long-term complications in adult spinal deformity patients having combined surgery a comparison of primary to revision patients. Spine (Phila Pa 1976) 26:973983, 2001

16. Linville DA, Bridwell KH, Lenke LG, Vedantam R, Leicht $P$ : Complications in the adult spinal deformity patient having combined surgery. Does revision increase the risk? Spine (Phila Pa 1976) 24:355-363, 1999

17. Ma Y, Passias P, Gaber-Baylis LK, Girardi FP, Memtsoudis SG: Comparative in-hospital morbidity and mortality after revision versus primary thoracic and lumbar spine fusion. Spine J 10:881-889, 2010

18. Mehta VA, Amin A, Omeis I, Gokaslan ZL, Gottfried ON: Implications of spinopelvic alignment for the spine surgeon. Neurosurgery 70:707-721, 2012

19. Passias PG, Soroceanu A, Smith J, Boniello A, Yang S, Scheer JK, et al: Postoperative cervical deformity in 215 thoracolumbar patients with adult spinal deformity: prevalence, risk factors, and impact on patient-reported outcome and satisfaction at 2-year follow-up. Spine (Phila Pa 1976) 40:283-291, 2015 
20. Scheer JK, Smith JS, Clark AJ, Lafage V, Kim HJ, Rolston JD, et al: Comprehensive study of back and leg pain improvements after adult spinal deformity surgery: analysis of 421 patients with 2-year follow-up and of the impact of the surgery on treatment satisfaction. J Neurosurg Spine 22:540553,2015

21. Schwab F, Blondel B, Chay E, Demakakos J, Lenke L, Tropiano $\mathrm{P}$, et al: The Comprehensive Anatomical Spinal Osteotomy Classification. Neurosurgery 74:112-120, 2014

22. Schwab FJ, Blondel B, Bess S, Hostin R, Shaffrey CI, Smith JS, et al: Radiographical spinopelvic parameters and disability in the setting of adult spinal deformity: a prospective multicenter analysis. Spine (Phila Pa 1976) 38:E803-E812, 2013

23. Schwender JD, Casnellie MT, Perra JH, Transfeldt EE, Pinto MR, Denis F, et al: Perioperative complications in revision anterior lumbar spine surgery: incidence and risk factors. Spine (Phila Pa 1976) 34:87-90, 2009

24. Smith JS, Klineberg E, Lafage V, Shaffrey CI, Schwab F, Lafage R, et al: Prospective multicenter assessment of perioperative and minimum 2-year postoperative complication rates associated with adult spinal deformity surgery. J Neurosurg Spine 25:1-14, 2016

25. Smith JS, Sansur CA, Donaldson WF III, Perra JH, Mudiyam R, Choma TJ, et al: Short-term morbidity and mortality associated with correction of thoracolumbar fixed sagittal plane deformity: a report from the Scoliosis Research Society Morbidity and Mortality Committee. Spine (Phila Pa 1976) 36:958-964, 2011
26. Smith JS, Shaffrey CI, Klineberg E, Lafage V, Schwab F, Lafage R, et al: Complication rates associated with 3-column osteotomy in 82 adult spinal deformity patients: retrospective review of a prospectively collected multicenter consecutive series with 2-year follow-up. J Neurosurg Spine 27:444457, 2017

\section{Disclosures}

Dr. Ames: employee at UCSF; consultant for Stryker, Medtronic, and DePuy; patent holder with Fish \& Richardson, PC; and royalties from Stryker and Biomet Spine.

\section{Author Contributions}

Conception and design: Ames, Lau. Acquisition of data: Lau. Analysis and interpretation of data: Lau. Drafting the article: Lau, Chan. Critically revising the article: all authors. Reviewed submitted version of manuscript: all authors. Approved the final version of the manuscript on behalf of all authors: Ames. Statistical analysis: Lau. Study supervision: Ames, Deviren.

\section{Correspondence}

Christopher P. Ames, Department of Neurological Surgery, University of California, San Francisco, 400 Parnassus Ave., A850, San Francisco, CA 94143. email: amesc@neurosurg.ucsf.edu. 